Japanese Psychological Research

1984, Vol. 26, No. 4, 231-234

Short Report

\title{
Group composition and conforming behavior in Japanese students
}

TIMOTHY P. WILLIAMS

Faculty of Foreign Languages, Osaka Gakuin University, Suita, Osaka 564

SHUNYA SOGON

Human Behavior Laboratory, College of Liberal Arts and Sciences, Osaka Gakuin University, Suita, Osaka 564

\begin{abstract}
A recent report suggested that a radical change was occurring in the response of British students to the Asch-type conformity experiment. The present study of Japanese students, however, shows no such change; nor did it show any signs of anticonformity as reported earlier. In comparison with students of other countries, Japanese students showed less conformist responses to the stranger groups; and more conformist responses to the familiar groups, e.g. to their own university's sport clubs. These results seem to support the conclusion that response to the Asch-type experiment is not universal but rather reflects cultural and situational factors.
\end{abstract}

Key words: conformity, anticonformity, group, foreigner effect, Japanese students.

Asch's (1956) experiments on social conformity have been replicated by many students with only slightly varying results. There have, however, been two notable exceptions. The first of these involved Japanese subjects. Frager (1970) found what he termed "substantial anticonformity". That is, he found that a third of his subjects gave responses which were neither correct nor the unanimousely incorrect judgements of the other subjects. The idea that Japanese subjects may show less conformist responses than American subjects runs counter to a very strong stereotype described, for example, by Gibney (1979). Japanese group processes, however, differ greatly from those of other societies ( $\mathrm{Na}$ kane, 1979). We would suggest that it is important to know whether subjects are among anonymous strangers or with people they know well. We would further suggest that the distinction between members and non-members of the group should be applied to the experimenter. Having a foreign rather than a native experimenter may explain the Japanese anticon-

1 The authors wish to thank Osaka Gakuin University and Ms. Yoshiko Ishii for much kind assistance. formity reported by Frager (1970).

The second exception to the usual series of replication occurred in the U.K. (Perrin \& Spencer, 1981) In an experimental group of university students, Perrin and Spencer found no evidence of the conformity found in Asch's original experiments. They were, however, able to elicit conformist responses in two rather different groups-young criminal offenders with a majority group of probation officers; and black immigrant youths with a majority group of peers and a white experimenter.

Our purposes in this experiment were threefold; 1) to see if the passage of time affects responses of Japanese students as in Perrin and Spencer $(1981) ; 2$ ) to see if the composition of the experimental groups affect the rate of conformity; and 3) to see if the presence of the foreign rather than native experimenter would produce anticonformity.

Method

\section{Subjects}

Subjects were 60 undergraduate students from a private university in Osaka. The students tend to be quite wealthy, but not 
Table 1

Results of experimental groups and effects of experimenter nationality

\begin{tabular}{|c|c|c|c|c|c|c|}
\hline \multirow{2}{*}{$\begin{array}{l}\text { Experimental } \\
\text { group }\end{array}$} & \multirow{2}{*}{$\mathcal{N}$} & \multirow{2}{*}{$\begin{array}{l}\text { Total number } \\
\text { of critical trials }\end{array}$} & \multicolumn{2}{|c|}{$\begin{array}{c}\text { Correct } \\
\text { responses }\end{array}$} & \multicolumn{2}{|c|}{$\begin{array}{l}\text { Pro-majority con- } \\
\text { forming errors }\end{array}$} \\
\hline & & & $F$ & $\%$ & $F$ & $\%$ \\
\hline $\begin{array}{l}\text { 'Friend' } \\
\text { (Club members) }\end{array}$ & 24 & 168 & 83 & 49 & 85 & 51 \\
\hline 'Stranger' & 36 & 252 & 162 & 64.3 & 70 & 27 \\
\hline \multicolumn{7}{|l|}{$\begin{array}{c}\text { Experimenter } \\
\text { nationality }\end{array}$} \\
\hline Non Japanese & 24 & 168 & 102 & 60.7 & 66 & 39.3 \\
\hline Japanese & 36 & 252 & 143 & 56.7 & 108 & 42.8 \\
\hline
\end{tabular}

highly motivated academically. Twentyfour of the students were from the university baseball or Kendo (Japanese fencing) clubs. The rest were volunteers for "an experiment in perception " including equal numbers of males and females.

\section{Procedure}

The procedure was similar to that described by Asch (1956) and Frager (1970). The instructions were translated into Japanese by bilingual speakers. The authors were also the experimenters, and read the instructions for the subjects. The nonJapanese author had spent 18 months in Japan.

The majority in the 'stranger' group were three paid participants (psychology students) from another university. The subjects believed them to be members of the same university. All were male. The majority group in the 'friend' condition was composed of three members from the same club. The experimenters ran each set of tests alternately. Thus the Japanese and foreign experimenters each ran half of the trials.

A post-test questionnaire was given to check on the subjects' eyesight and their understanding of the instructions. Subjects were also checked for previous knowledge of the experiment's purpose and for suspition. One subject was dropped out on the way and another one was recruited to make up the number.

\section{Results}

\section{Group Membership}

In Table 1, we can see that there was a significant difference in the rates of conforming responses for different conditions of 'friend' and 'stranger' $\left(\chi^{2}=9.49\right.$, $p<.01$ ).

\section{Experimenter}

There was no significant difference between rates of conforming responses for the different experimenters.

\section{Anticonformity}

There was no evidence of anticonformity in any condition.

\section{Comparison of Results}

In Table 2, we can see a summary of results from the studies already referred to, and one other replication by a Japanese experimenter in Japan. If we take the comparable conditions in Frager's (1970) and Sako's (1979) experiments, i.e., anonymous stranger groups, we can see that the rates of Japanese conformity are rather similar; and lower than those found by Asch. The rates in this condition are also lower than those found in other countries with the exception of the U.K. (Perrin \& Spencer, 1981). If we look at the 'friend' condition, we can see that the rate of conformity is as high as the highest rates 
Table 2

Results of experimental groups from different countries

\begin{tabular}{|c|c|c|c|c|c|c|}
\hline \multirow[t]{2}{*}{ Country } & \multirow{2}{*}{$\mathcal{N}$} & \multirow{2}{*}{$\begin{array}{l}\text { Total number } \\
\text { of critical trials }\end{array}$} & \multicolumn{2}{|c|}{$\begin{array}{l}\text { Correct } \\
\text { responses }\end{array}$} & \multicolumn{2}{|c|}{$\begin{array}{l}\text { Pro-majority con- } \\
\text { forming errors }\end{array}$} \\
\hline & & & $F$ & $\%$ & $F$ & $\%$ \\
\hline U.S.A.† & 31 & 217 & 145 & 66.8 & 72 & 33.2 \\
\hline Braziltt & 33 & 231 & 152 & 65.9 & 79 & 34.1 \\
\hline Lebanontt & 48 & 336 & 234 & 69.1 & 102 & 30.9 \\
\hline Rhodesiatt & 20 & 140 & 69 & 49.3 & 71 & 50.7 \\
\hline Hong Kongt† & 14 & 98 & 67 & 68.4 & 31 & 31.6 \\
\hline Fijittt & 51 & 357 & 192 & 53.8 & 165 & 46.2 \\
\hline Japan (1966) $+t+\uparrow$ & 45 & & & & & 25 \\
\hline $\begin{array}{l}\text { Japan (1979) } 1+\uparrow+\uparrow \\
\text { Japan }(1984)+\uparrow+\uparrow+\uparrow\end{array}$ & & & & & & 22 \\
\hline 'friend' & 24 & 168 & 83 & 49 & 85 & 51 \\
\hline 'stranger' & 36 & 252 & 162 & 64.3 & 70 & 27 \\
\hline
\end{tabular}

elsewhere, i.e. Fiji and Rhodesia.

\section{Discussion}

The results do not suggest that there have been radical changes in Japanese students' responses comparable to those that seem to have occurred in the U.K. They seem to suggest rather that there has been very little change, since Frager (1970) and Sako (1979). The Japanese subjects conform to unanimously incorrect judgements only about $25 \%$ of the time, when the other members of the group are not known to them previously.

It also seems clear that when the other members of the group are previously known to the subjects, at least in such established groups as sport clubs, subjects are more likely to conform. Kinoshita (1964) showed something similar in Japanese high-school students, where the students were more likely to conform to others' opinions in groups which showed 'highly cohesive' sociograms. All the subjects in this experiment were from the same school. Therefore, even the members of the 'low-cohesiveness' groups were probably not strangers to each other. This work, taken in conjunction with works surveyed by Misumi (1978), make it reasonable to argue that it is membership of a previousely established group which makes individuals in this experiment more likely to conform to the incorrect views of others. It is notable that in one of the two other experiments showing high rates of conformity (c.f. Table 2) the subjects and ' confederates' were taken from the same teacher-training courses (Chandra, 1973). It is not clear, though it seems probable, that this was also the case in the Rhodesian experiment (Whittaker \& Meade, 1967). If subjects and ' confederates' did indeed know each other previously, then there may be evidence of a cross-cultural tendency to conform more to the opinions of "people-previously-known-to-you".

The post-test questionnaire showed that, in general, the subjects felt they knew the correct answer but lacked confidence in their judgements. They did not, as Asch found, actually believe that their incorrect judgements were correct, nor did they say that they were worried about being in conflict with other members of the group. Members of sport clubs, however, not surprisingly expressed more confidence in 
their powers of judgement, but were inclined to blame the lighting, seating arrangements or optical illusions for their incorrect judgements. Though the questionnaires are necessarily subjective, they do tend to confirm that group membership was a significant factor in subjects' responses.

The other notable feature of this study was the absence of any anticonformity as reported by Frager (1970). The hypothesis that this would be a response to a foreign experimenter was therefore not confirmed. This seems to support Perrin and Spencer hypothesis that the results of the Asch-type experiments reflect particular social and cultural pressures at the particular time. The campus where Frager performed his research was about to be closed by a wave of radical student protest (often directed against the United States) of the kind never seen before. Anticonformity may well then have been a symptom of the unusual conditions of the time and the place.

In using already established groups rather than arbitrary groups of strangers, this study has gone a little way toward showing how people behave in ordinary situations. Much more research is needed to extrapolate from many similar kinds of experiments to 'real 'behavior. The results of this study perhaps suggest that it is time that such work was done outside laboratory.

\section{References}

Asch, S. E. 1956 Studies of independence and conformity: 1. A minority of one against a unanimous majority. Psychological Monographs, Vol. 70, No. 9.

Chandra, S. 1973 The effects of group pressure in perception: A cross-cultural conformity study in Fiji. International Journal of Psychology, 8, 3739.

Frager, R. 1970 Conformity and anticonformity in Japan. Journal of Personality and Social Psy. chology, 15, 203-210.

Gibney, F. 1979 Japan: The fragile superpower, Tokyo: Charles E. Tuttle.

Kinoshita, T. 1964 The effects of group cohesiveness and task importance upon conformity behavior. Japanese Journal of Psychology, 35, 181191. (In Japanese with English Abstract)

Misumi, J. (Ed.) 1978 Social psychology in Japan. Osaka: Osaka University Publication.

Nakane, C. 1979 Japanese society. London: Penguin Books.

Perrin, S., \& Spencer, C. 1981 Independence or conformity in the Asch experiment as a reflection of cultural and situational factors. British Journal of Social Psychology, 20, 205-209.

Sako, S. 1979 Asch experiment on conformity: A replication. Unpublished Master's thesis. University of Osaka.

Whittaker, J. O., \& Meade, R. D. 1967 Social pressure in the modification and distortion of judgement: A cross-cultural study. International Journal of Psychology, 2, 109-113.

(Received May 9, 1983; accepted July 14, 1984) 